\title{
Adverse Event Coordinator
}

National Cancer Institute

\section{Source}

National Cancer Institute. Adverse Event Coordinator. NCI Thesaurus. Code C51799.

A designated person who is trained and responsible for coordinating adverse event

review, tracking, surveillance and reporting activities within a clinical institution or clinical trial. 